Geront. clin. 1974;16:235-237

\title{
Contents, Vol. 16, No. 5-6, 1974
}

\section{Editorial 239}

Strouthidis, T. M. (Hastings): Medical Requirements of the Day Hospital

Saunders, B. M. (Bromley): Nurse's Role in Day Care

248

Bagnall, M. K. (Hastings): Day Care and Social Needs 253

Thompson, M. K. (Croydon): A General Practitioner Looks at Day Care

Hildick-Smith, M. (Canterbury): A Typical Journey to and from the Day Hospital 263

Symonds, P. C. (Lewes): Social Services and Day Care

270

Ransome, H. E. (Bromley): Physiotherapy in the Geriatric Day Hospital

Higgins, J. (Leatherhead): Occupational Therapy in the Social Services

281

Glass, S. C. (Alcester): Workshops for the Elderly

285

Goldstone, H. (Hastings): Planning a Day Hospital 289

Ellis, L. J. (Croydon): Designing Day Hospitals 294

Hall, M. R. P. (Southampton): Day Care and Society

Greenfield, P. R. (London): A Departmental View 307

Porter, K. R. D. (Croydon): A Regional View 315

Matthews, J. C. (Lewes): The Social Services View 318 